\title{
LEVANTAMENTO QUANTITATIVO DAS ESPÉCIES UTILIZADAS NA ARBORIZAÇÃO URBANA DO MUNICÍPIO DE TAUÁ - CEARÁ
}

Silvio César Gomes de Lima ${ }^{1}$, Arcanja Marília Moreira Gomes ${ }^{2}$, Vanessa Gonçalves de Sousa ${ }^{2}$, lone Moraes de Oliveira ${ }^{2}$, Selma Freire de Brito ${ }^{3}$

${ }^{1}$ Professor Doutor da Universidade Estadual do Ceará-UECE, Faculdade de Educação, Ciências e Letras dos Inhamuns-CECITEC, Tauá, Ceará.

${ }^{2}$ Graduada em Ciências Biológicas, Universidade Estadual do Ceará-UECE, Faculdade de Educação, Ciências e Letras dos Inhamuns- CECITEC, Tauá, Ceará.

${ }^{3}$ Professora Doutora da Universidade Estadual do Ceará-UECE, Faculdade de Educação, Ciências e Letras dos Inhamuns-CECITEC, Tauá, Ceará. selma.brito@uece.br

Recebido em: 04/10/2019 - Aprovado em: 30/11/2019 - Publicado em: 15/12/2019 DOI: 10.18677/EnciBio_2019B37

\begin{abstract}
RESUMO
A arborização urbana refere-se a vegetação encontrada nas cidades, sendo importante para garantir a qualidade de vida das pessoas que residem nestes ambientes. A falta de planejamento urbano é vista por muitos autores como uma dificuldade para a efetivação desse meio de bem estar, além disso, tem se caracterizado pelo elevado índice de uso de espécies exóticas. Nesse trabalho o objetivo foi realizar um levantamento das espécies arbóreas que compõe a arborização urbana do município de Tauá, Ceará. A pesquisa foi realizada através de um censo qualitativo, com levantamento de campo. Durante o qual todos os bairros de Taúa foram visitados e os nomes populares, científicos e a origem das espécies foram identificados. Após a coleta, foi construído uma tabela com os dados obtidos e calculado a frequência relativa e índice de diversidade de Shannon. Durante o levantamento foram observadas 4087 árvores distribuídas em 15 famílias e 21 espécies. Meliaceae e Fabaceae são as famílias botânicas mais representadas. Além disso, observou-se uma elevada ocorrência de espécies exóticas como Azadiractha indica, espécie exótica e considerada invasora em algumas regiões do mundo. Portanto, apesar de bem arborizada a diversidade de espécies é baixa e a espécie mais utilizada na arborização urbana de Tauá, trata-se de uma espécie exótica. A partir deste estudo espera-se que sejam tomadas medidas para adequar a arborização urbana desta cidade com o uso de espécies nativas.
\end{abstract}

PALAVRAS-CHAVE: Espécies Exóticas, Espécies Nativas, Levantamento botânico

\section{QUANTITATIVE LISTING OF SPECIES USED IN URBAN TREE ORGANIZATION OF TAUÁ - CEARÁ}

\section{ABSTRACT}

Urban afforestation refers to vegetation found in cities and is important to ensure the quality of life of people living in these environments. The lack of urban planning is seen by many authors as a difficulty for the realization of this means of well-being. Moreover, it has been characterized by the high use of exotic species. In this work the objective was to conduct a survey of the tree species that make up the urban 
afforestation of Tauá, Ceará. The research was conducted through a qualitative census, with field survey. During which all Taúa neighborhoods were visited and the popular, scientific names and origin of the species were identified. After collection, a table was constructed with the data obtained and the relative frequency and Shannon diversity index calculated. During the survey, 4087 trees distributed in 15 families and 21 species were observed. Meliaceae and Fabaceae are the most represented botanical families. In addition, there was a high occurrence of exotic species such as Azadiractha indica, exotic species and considered invasive in some regions of the world. Therefore, although well wooded the diversity of species is low and the most used species in the urban forestation of Tauá, it is an exotic species. From this study it is expected that measures will be taken to adapt the urban afforestation of this city with the use of native species.

KEYWORDS: Exotic Species, Native Species, Botanic survey

\section{INTRODUÇÃO}

A qualidade de vida em áreas urbanas está diretamente relacionada a vários fatores que estão reunidos na infraestrutura, no desenvolvimento econômicosocial e àqueles ligados à questão ambiental. A arborização urbana refere-se a toda cobertura vegetal de porte arbóreo existente nas cidades (LACERDA et al., 2013).

O estudo da arborização urbana vai além da composição fitossociológica, uma vez que além do aspecto de embelezamento, as plantas nas zonas urbanas são responsáveis pela redução da amplitude térmica, diminuem temperaturas extremamente altas, controlam a direção e a velocidade dos ventos (LOCKE; BAINE, 2015). Portanto, a arborização tem influência direta sobre o bem estar do homem, em virtude dos benefícios que proporciona ao meio, fornece abrigo e alimento à fauna, embeleza pelo variado colorido que exibe, e propiciam sombra e lazer nos parques, jardins, praças, ruas $e$ avenidas das cidades (SCHALLENBERGER, MACHADO, 2013).

Assim as áreas verdes constituem um fator importante para a saúde da população urbana. Uma vez que, além da beleza que proporciona ao ambiente desempenha um papel ecológico relevante (GONÇALVES, 2015). Porém, quando o processo de implementação da vegetação nas áreas urbanas é feito sem planejamento pode acarretar problemas, como o uso inadequado de espécies (MELO; PIACENTINI, 2011). Contudo, a ausência de planejamento da arborização urbana tem sido recorrente nas cidades brasileiras, incidindo em erros como na escolha das espécies (CRISPIM et al., 2017; ROCHA et al., 2018; SARTORI et al., 2019).

Atualmente, são consideradas tanto espécies nativas quanto exóticas para a arborização urbana. Porém o uso de espécies nativas deve ser priorizado e de exóticas evitada (VIEIRA et al., 2016). Na maioria das cidades observa-se uma predominância da utilização de espécies exóticas na arborização urbana. O que pode resultar em um problema ambiental, quando estas espécies exóticas se tornam invasoras. Embora exista esta recomendação, estudos recentes sobre o levantamento da composição da arborização urbana mostraram que a maioria das espécies catalogadas em levantamentos da vegetação urbana são espécies exóticas (SANTOS et al., 2015; ROCHA et al., 2018). Além dessa questão, a arborização urbana não leva em consideração a incorporação de espécies que possam fornecer alimento para a fauna local (SARTORI et al., 2019). A falta de 
planejamento urbano, também é um problema que dificulta um planejamento da arborização adequado, uma vez que os edifícios, bem como a largura inadequada das passarelas, tornam-se verdadeiros obstáculos para o plantio de árvores (SARTORI et al., 2019).

De maneira geral, os estudos sobre arborização urbana mostram que em sua maioria observa-se uma alta frequência de uma única espécie, além do uso frequente e em abundância de espécies exóticas (SILVA et al. 2015; OLIVEIRANEVES et al., 2016; CRISPIM et al., 2017; ROCHA et al., 2018). De acordo com Ferreira e Amador (2013), para que sejam evitados problemas relacionados ao plantio, é necessário planejar uma arborização diversificada, garantindo a preservação da fauna e da biodiversidade vegetal. Somado a isso, Sartori et al. (2019), ressaltam à escassez de publicações abordando a silvicultura urbana no Brasil.

Portanto, estudos sobre as espécies utilizadas na arborização urbana surgem como uma ferramenta para aperfeiçoar este processo e orientar sua execução. Assim, o objetivo deste trabalho foi realizar um levantamento quantitativo das espécies arbóreas que compõe a arborização urbana do município de Tauá, Ceará.

\section{Local de estudo}

\section{MATERIAL E MÉTODOS}

O município de Tauá (Figura 1), situa-se na Microrregião do Sertão dos Inhamuns, na Mesorregião dos Sertões Cearenses, entre as coordenadas 6음' 11" Latitude (S) e 40 17' 34" Longitude (WGr), no Sudoeste do Estado do Ceará, Brasil. O clima da região é do tipo tropical quente semiárido, temperatura média chega de $26^{\circ}$ a $28^{\circ} \mathrm{C}$. A pluviosidade é em torno de $597,2 \mathrm{~mm}$, o período chuvoso ocorre entre os meses de Fevereiro a Abril, o relevo caracteriza-se por depressões sertanejas e maciços residuais, os solos são Litólicos, planossolo solódico e Podzólico vermelhoamarelo. A vegetação da região caracteriza-se por uma Caatinga arbustiva aberta. $O$ município apresenta extensão territorial de $4.018,162 \mathrm{~km}^{2}$ e população de 57.914 habitantes (IPECE, 2015).

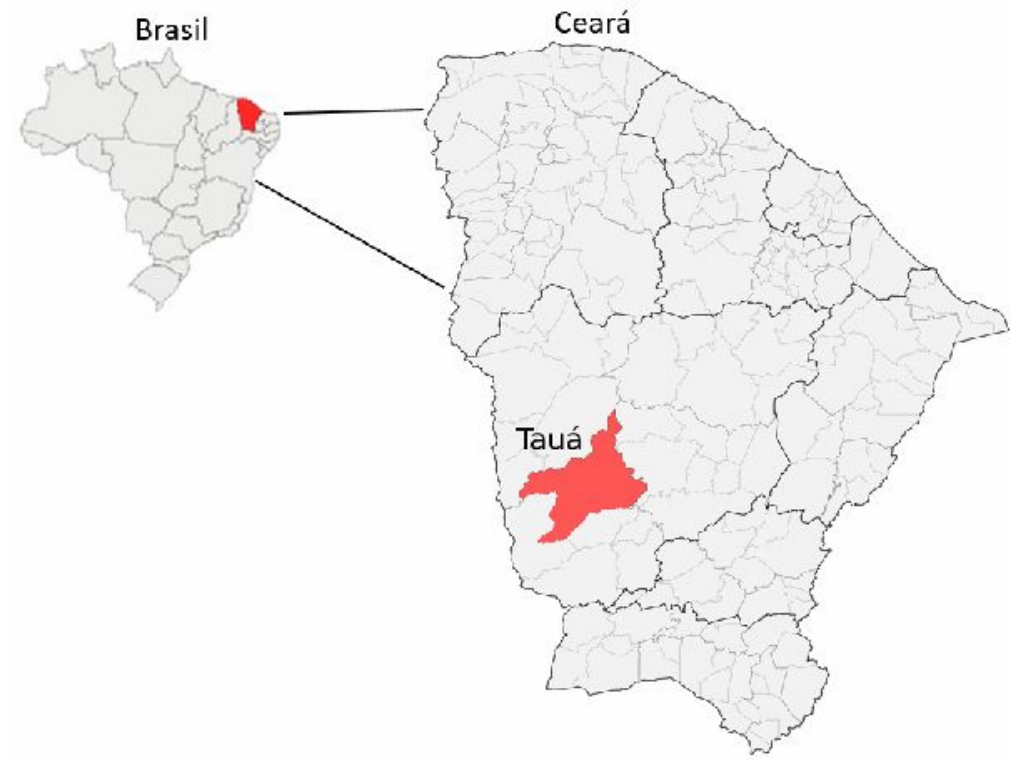

FIGURA 1: Localização do município de Tauá, Ceará.

Fonte: Autores 


\section{Levantamento das espécies}

Durante a coleta de campo foram visitadas todas as ruas da cidade para a contagem direta dos indivíduos arbóreos. Assim, a coleta de dados foi realizada em 214 ruas e avenidas dos bairros: Cidade Leste, Cidade Nova, Alto do Cruzeiro, Alto Nelândia, Aldeota, Meireles, Colibris, Vila Jathai, Bezerra e Sousa, Alto Brilhante, Centro, Tauazinho, Coab, São Geraldo, Rabeca, Domingos Gomes, São Geraldo 2 e ProUrb.

A amostragem da arborização urbana de Tauá foi realizada através de um estudo quantitativo, determinada como censo. Durante o levantamento, utilizouse uma ficha para coletar os seguintes dados: nome vulgar, nome científico e origem (nativa e exótica). Com auxílio da literatura especializada realizou-se a classificação botânica das plantas inventariadas, relacionadas à família, nome científico e origem.

\section{Análise estatística}

Os dados coletados nas visitas em campo foram transformados em tabelas e também calculada a frequência relativa (FR) conforme Magurran (2004), pela fórmula: $\mathrm{FRi}=(\mathrm{FAi} / \Sigma \mathrm{FA}) \times 100$. Onde: $\mathrm{FRi}=$ frequência relativa da variável $\mathrm{i} ; \mathrm{FAi}=$ frequência absoluta da variável i. Também foi calculado o Índice de diversidade de Shannon $\left(\mathrm{H}^{\prime}\right)$, quanto maior o valor de $\mathrm{H}^{\prime}$, maior a diversidade florística da área em estudo (MAGURRAN, 2004).

Os resultados dos cálculos foram apresentados em tabelas e gráficos de barra. Os gráficos foram construídos utilizando o programa SimaPlot, versão 12.5.

\section{RESULTADOS E DISCUSSÃO}

Os dados obtidos no levantamento mostram que na cidade de Tauá foram catalogados um total de 4.087 árvores distribuídas em 15 famílias e 21 espécies (Tabela 1).

TABELA 1. Espécies, família, quantidade (Q) e frequência relativa (FR) da composição arbórea da cidade de Tauá.

\begin{tabular}{ccccc}
\hline Nome Popular & Nome científico & Família & Q & FR (\%) \\
\hline Acacia & Senna siamea L. & Fabaceae & 569 & 13,92 \\
Algaroba & Prosopis Juliflora (Sw.) DC & Fabaceae & 78 & 1,91 \\
Azeitona preta & Syzygium cumini (L.) & Myrtaceae & 17 & 0,42 \\
& Skeels & & & 0,49 \\
Castanholeira & Terminalia catappa L. & Combretaceae & 20 & 0,15 \\
Coqueiro & Cocos nucifera L & Arecaceae & 6 & 0,07 \\
Flamboyant & Delonix regia (Hook.) Raf. & Fabaceae & 3 & 0,02 \\
Juazeiro & Ziziphus joazeiro Mart & Ramanáceae & 1 & 0,07 \\
Laranjeira & Citrus sinensis (L.) Osbeck & Rutaceae & 3 & 0,02 \\
Limoeiro & Citrus limon (L.) Osbeck & Rutaceae & 1 & 0,05 \\
Mamão & Carica papaya & Caricaceae & 2 & 0,22 \\
Mangueira & Mangifera indica L. & Anacardiaceae & 9 & 73,57 \\
Nim & Azadiractha indica A.Juss & Meliaceae & 3007 & 1,52 \\
Palmeira & Chrysalidocarpus & Palmae & 62 & 1 \\
Pau Branco & Iutescens & & & \\
& Auxemma oncocalyx (Fr. & Boraginaceae & 13 & 0,32 \\
\hline
\end{tabular}




\begin{tabular}{ccccc}
\hline $\begin{array}{c}\text { Pau Brasil } \\
\text { Pau ferro }\end{array}$ & $\begin{array}{c}\text { Paubrasilia echinata Lam. } \\
\text { Caesalpinia ferrea (Mart. } \\
\text { ex Tul.) L.P.Queiroz. }\end{array}$ & $\begin{array}{c}\text { Caesalpiniaceae } \\
\text { Caesalpinoideae }\end{array}$ & 1 & 0,02 \\
Pinha & $\begin{array}{c}\text { Annona squamosa L. } \\
\text { Sabiá }\end{array}$ & Annonaceae & 1 & 0,02 \\
& $\begin{array}{c}\text { Mimosa caesalpiniaefolia } \\
\text { Benth. }\end{array}$ & Mimosoideae & 1 & 0,02 \\
Sempre verde & Ficus benjamina L. & Moraceae & 290 & 7,10 \\
Siriguela & Spondias purpúrea L. & Anacardiaceae & 1 & 0,02 \\
Umbu & Spondias tuberosa Arruda & Anacardiaceae & 1 & 0,02 \\
\hline Total & & & $\mathbf{4 0 8 7}$ & $\mathbf{1 0 0}$ \\
\hline
\end{tabular}

Fonte: Autores.

Com relação ao número de indivíduos por espécie, constatou-se que $90,56 \%$ do total de exemplares foram representados por apenas três espécies: Azadirachta indica, com 3.007 (73,57\%); Senna siamea, com 569 indivíduos $(13,92 \%)$; e Ficus benjamina, com 290 indivíduos (7,10\%), totalizando 3.893 indivíduos, representando 94,59\% dos indivíduos amostrados (Tabela 1).

Os resultados indicam que existe uma grande homogeneidade dos indivíduos inventariados, com um valor de índice de diversidade de Shannon de $H^{\prime}=1,02$, indicando uma baixa diversidade nas espécies vegetais utilizadas na arborização urbana de Tauá. Sartori et al. (2019), encontraram um índice de diversidade de $\mathrm{H}=4,02$ na arborização urbana de favelas do Rio de Janeiro, segundo os autores considerado alto. Portanto, um índice de diversidade bem acima do observado neste estudo. Resultados obtidos por Crispim et al. (2017), na cidade e Baixio-CE, mostraram uma baixa diversidade das espécies arbóreas nas vias públicas, a semelhança deste estudo.

Azadiractha indica, Ficus benjamina e Senna siamea destacam-se como as espécies exóticas mais abundantes na arborização urbana de Tauá (Tabela 1). Com isto, faz-se um alerta, uma vez que espécies exóticas podem passar por um processo de naturalização e tornarem-se invasoras, acarretando variados problemas. Em um estudo realizado por Crispim et al. (2017), Azadiractha indica e Ficus benjamina, também aparecem com uma alta frequência, 68 e 19\% respectivamente, na arborização urbana da cidade de Baixio - CE.

Azadiractha indica é a espécie com maior número de indivíduos, representando $73,57 \%$ dos indivíduos amostrados, com 3.007 dos 4.087 indivíduos. O que constitui uma grave ameaça, uma vez que esta espécie é considerada invasora e que pode causar graves problemas ambientais (FABRICANTE, 2014; FABRICANTE, 2017). Similaridades são encontradas em Crispim et al. (2014), em que Azadiractha indica apareceu em maior porcentagem na arborização do centro da cidade de Pombal - PB. Crispim et al. (2017), cidade de Baixio - CE, durante um levantamento identificaram uma alta área de espécies exóticas destacando-se a presença de Azadiractha indica.

Barcellos et al. (2012), recomenda que uma única espécie não ultrapasse a porcentagem de 10 a $15 \%$ do total de árvores viventes em um mesmo bairro ou região. Desde modo, observou-se que as espécies com maior abundância estão ultrapassando essa porcentagem recomendada, sendo necessário criar um projeto com planejamento adequado da arborização. 
A uniformidade das espécies utilizadas na arborização de Tauá, também aparece quando observam-se as frequências das famílias botânicas, em que Meliaceae e Fabaceae, apresentam uma frequência relativa de mais de $75 \%$ e de $15 \%$, respectivamente, com total de $90 \%$. Enquanto, outras famílias botânicas foram representadas com menos de $5 \%$ em frequências relativas durante o levantamento (Figura 2).

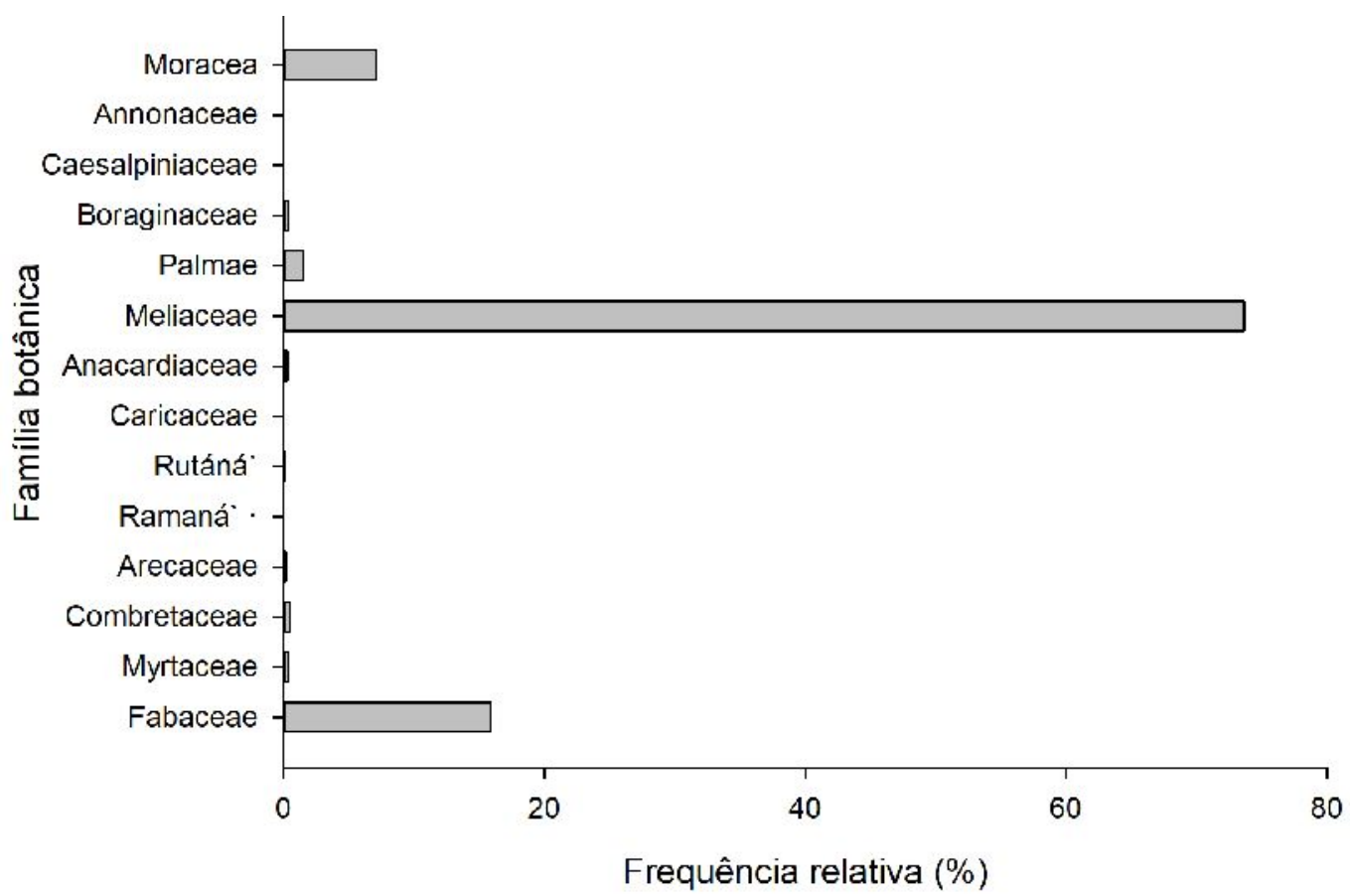

FIGURA 2: Frequência relativa das famílias botânicas encontradas na arborização urbana de Tauá, Ceará. Fonte: Autores.

Estudos sobre levantamentos da arborização urbana, têm mostrado que ocorre a predominância de algumas famílias, como descrito por Zea et al. (2015) e Edson-Chaves et al. (2019). Estes estudos também realizados na região Nordeste, observaram a predominância da família Meliaceae, caracterizado pelo uso intenso de Azadiractha indica, na arborização urbana da região como observado para Tauá.

Das 21 espécies amostradas, apenas sete são espécies nativas do Brasil, representadas por Ziziphus joazeiro, Auxemma oncocalyx, Paubrasilia echinata, Caesalpinia férrea, Mimosa caesalpiniaefolia, Spondias purpúrea e Spondias tuberosa. Sendo $A$. oncocalyx a espécie nativa com maior representatividade (13 indivíduos). A maioria das espécies encontradas nas ruas de Tauá são exóticas. Além disso, apresentam usos variados, sendo nove espécies frutíferas, sete florestal/madeireira e cinco ornamentais (Quadro 1).

QUADRO 1. Origem e uso, das espécies amostradas na composição arbórea da cidade de Tauá, Ceará.

\begin{tabular}{ccc}
\hline Nome científico & Origem & Uso \\
\hline Senna siamea L. & Exótica & Ornamental \\
Prosopis Juliflora (Sw.) DC & Exótica & Florestal/madeireira \\
Syzygium cumini (L.) Skeels & Exótica & Frutífera
\end{tabular}




\begin{tabular}{ccc}
\hline Terminalia catappa L. & Exótica & Florestal/madeireira \\
Cocos nucifera L & Exótica & Frutífera \\
Delonix regia (Hook.) Raf. & Exótica & Ornamental \\
Ziziphus joazeiro Mart & Nativa & Florestal/madeireira \\
Citrus sinensis L. Osbeck & Exótica & Frutífera \\
Citrus limon L. Osbeck & Exótica & Frutífera \\
Carica papaya & Exótica & Frutífera \\
Mangifera indica L. & Exótica & Frutífera \\
Azadiractha indica A.Juss & Exótica & Ornamental \\
Chrysalidocarpus lutescens & Exótica & Ornamental \\
Auxemma oncocalyx (Fr. All.) Baill & Nativa & Florestal/madeireira \\
Paubrasilia echinata Lam. & Nativa & Florestal/madeireira \\
Caesalpinia ferrea (Mart. ex Tul.) & Nativa & Florestal/madeireira \\
L.P.Queiroz. & & \\
Annona squamosa L. & Exótica & Frutífera \\
Mimosa caesalpiniaefolia Benth. & Nativa & Florestal/madeireira \\
Ficus benjamina L. & Exótica & Ornamental \\
Spondias purpúrea L. & Nativa & Frutífera \\
Spondias tuberosa Arruda & Nativa & Frutífera \\
\hline
\end{tabular}

Fonte: Autores.

Assim, como observado neste levantamento realizado em Tauá, é recorrente 0 uso de espécies exóticas na arborização urbana. Uma pesquisa realizada por Edson-Chaves et al. (2019), nas cidades de Beberibe e Cascavel, no Ceará, foram amostrados um total de 18 espécies sendo que apenas três eram nativas. Este panorama, do uso de espécies exóticas para a arborização ocorre em outras regiões do Pais, Rocha et al. (2018), ao estudarem a arborização urbana do município de Itapuã do Oeste, Rondônia, demonstraram pouca diversidade e a maioria das plantas inventariadas eram de origem exótica.

A proporção entre indivíduos nativos e exóticos, amostrados é quase $100 \%$, para espécies exóticas (Figura 3A). Além disso, embora mais de 30\% das espécies sejam nativas, a proporção de indivíduos destas espécies foi muito baixa, com espécies exóticas representando mais de 60\% (Figura 3B).
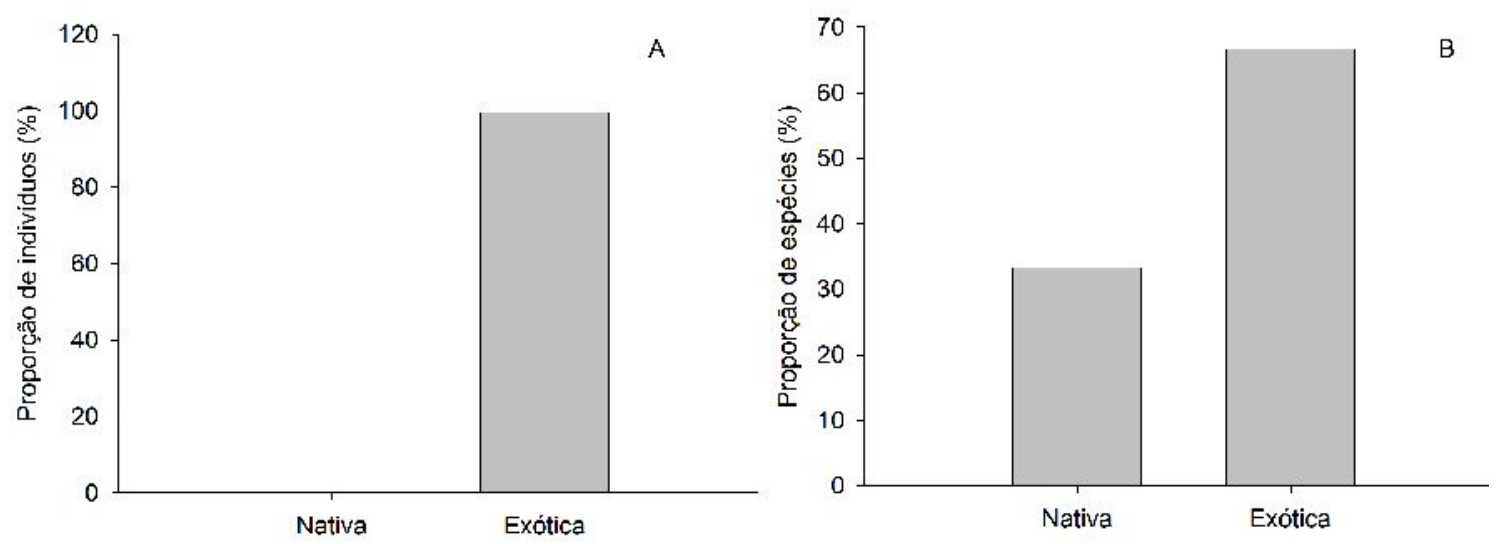

FIGURA 3: Proporção entre indivíduos amostrados de espécies nativas e exóticas (A) e proporção entre o número de espécie exótica e nativas que compõe a arborização urbana de Tauá, Ceará. Fonte: Autores. 
Silva et al. (2015), encontraram um percentual de espécies nativas de $38 \%$ na arborização das praças do município de Itapuranga-GO, semelhante aos resultados observados para Tauá. Assim, recomenda-se que estudos sejam realizados para identificar espécies nativas com características semelhantes e que possam ser usadas com sucesso e sem consequências negativas para o meio. Uma vez que as espécies exóticas podem vir a competir com as nativas (SARTORI et al., 2019). De acordo com Crispim et al. (2014), uma possibilidade da predominância de espécies exóticas na arborização de via públicas talvez seja devido à inexistência de políticas públicas e ações de educação ambiental por parte do poder público municipal direcionadas a população, contribuindo para que esses realizem ações isoladas, sem nenhum planejamento.

Assim, para o município de Tauá, destaca-se que é muito importante que os órgãos públicos responsáveis pela parte ambiental das cidades, desenvolvam mais projetos que possam incentivar a população de Tauá a plantar espécies nativas, buscando assim uma forma de ir substituindo as exóticas presentes na cidade. Foi verificado também, que quase $60 \%$ das espécies levantadas durante a arborização, apresentam dispersão zoocórica. Observou-se ainda que cerca de 13\% apresentam dispersão barocórica (Figura 4).

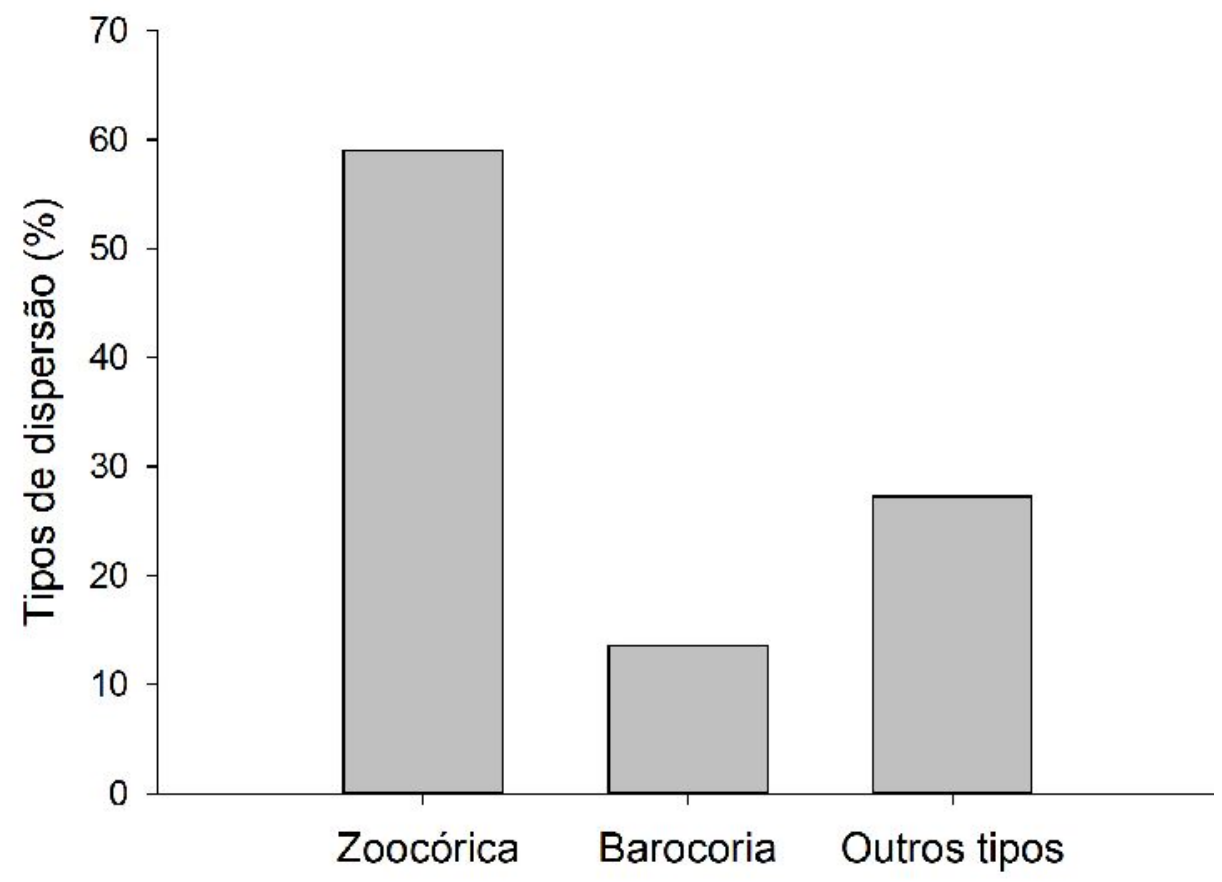

FIGURA 4: Tipo de dispersão de Frutos/sementes das espécies que compõe a arborização urbana de Tauá, Ceará. Fonte: Autores.

Assim, destaca-se a importância de espécies frutíferas nos centros urbanos como uma possibilidade de atrativo para a fauna e permite que estas não sejam extintas destas áreas. Por outro lado, ressalta-se a alta probabilidade de dispersão das espécies exóticas através dos frutos/sementes. Sartori et al. (2019), alertam para o fato de que espécies exóticas dispersas pelos pássaros pode ajudar na disseminação das mesmas para formações florestais próximas das cidades. 


\section{CONCLUSÃO}

No levantamento da arborização urbana do município de Tauá, observouse uma baixa diversidade de espécies e uma alta ocorrência de poucas espécies, sendo a maior parte da arborização desta cidade realizada com espécies exóticas. Isto indica que a arborização foi feita sem um planejamento quanto as espécies que seriam utilizadas. Observou-se ainda que, muitas espécies utilizadas são frutíferas o que indica que oferecem recursos para a fauna local.

\section{AGRADECIMENTOS}

O presente trabalho agradece a colaboração de Míriã Henrique Sá Lima e Cícera Lima da Silva, durante o levantamento da vegetação na cidade de Tauá.

\section{REFERÊNCIAS}

BARCELLOS, A.; WOJCIKIEWICZ, C.R; LUBASZEWSKI, E.A.; Mazuchowski, J.Z.; Conceição, J.R.; Leal, L.; Medeiros, M.L.M.; Conte, P.A.; Karvat, S.G.; Ahrens, S. Manual para Elaboração do Plano Municipal de Arborização Urbana. P. B. Gomes (Org.), Ministério Público do Paraná, 2012. Disponível em:<https://ainfo.cnptia.embrapa.br/digital/bitstream/item/96121/1/2013-SergioAManual-PMARB.pdf>.

CRISPIM, D.L.; SILVA, M.A.; CHAVESS, A.D.C.G.; ALMEIDA, R.R.P.; FREITAS, A.J.F. Diagnóstico da arborização urbana do centro da cidade de Pombal-PB. Revista Verde, v. 9, n.1, p.191-196, 2014. Disponível em:< https://www.gvaa.com.br/revista/index.php/RVADS/article/view/2707/2160>.

CRISPIM, D.L.; MENESES, J.A.D.; VIEIRA, A.S.A.; ARAÚJO, L.M.; CRUZ, J.S.C.; SILVA, J.I.S. Levantamento quali-quantitativo da arborização urbana da cidade de Baixio - CE. Divulgação Científica e Tecnológica do IFPB, n. 36, p. 99-106, 2017. Disponível em: <10.18265/1517-03062015v1n36p99-106>. doi:10.18265/151703062015v1n36p99-106.

EDSON-CHAVES, B.; DANTAS, A.G.B.; LIMA, N.S.; PANTOJA, L.D.M.; MENDES, R.M.S. Avaliação qualiquantitativa da arborização da sede dos municípios de Beberibe e Cascavel, Ceará, Brasil. Ciência Florestal, v. 29, n. 1, p. 403-416, 2019. Disponível em:<http://dx.doi.org/10.5902/1980509829939>.

doi: 10.5902/1980509829939.

FABRICANTE, J. R. Azadirachta indica. In: FABRICANTE, J. R. Plantas exóticas e exóticas invasoras da Caatinga. Florianópolis: Bookess, p. 23-30.2014.

FABRICANTE, J. R.; SANTOS, J. P. B.; ARAÚJO, K. C. T.; COTARELLI, V. M. Utilização de espécies exóticas na arborização e a facilitação para o estabelecimento de casos de invasão biológica. Biotemas, v. 30, n. 1, p.55-63, 2017.

em:<https://periodicos.ufsc.br/index.php/biotemas/article/view/2175-

925.2017v30n1p55>. 
FERREIRA, E. S.; AMADOR, M. B. M. Arborização urbana: a questão das praças e calçadas no município de Lajedo-PE e a percepção da população. Fórum Ambiental da Alta Paulista, v. 9, n. 4, p. 59-78, 2013. Disponível em: https://www.amigosdanatureza.org.br/publicacoes/index.php/forum_ambiental/article/ view/614. doi: 10.17271/19800827942013614.

GONÇALVES, W. Diagnose qualitativa de florestas urbanas. Viçosa: o autor, 2015. 93p.

IPECE. Perfil básico municipal de Tauá. Disponível em: https://www.ipece.ce.gov.br/perfil_basico_municipal/2015/Taua.pdf. Acesso em: 21. 06. 19.

MAGURRAN, A.E. 2004. Measuring Biological Diversity. Blackwell Science Ltd, Oxford.

MELO, E.F.R.Q.; PIACENTINI, C.A.M. Diversidade da Arborização Urbana no Município de Colorado (RS). Revista Ambiência, v. 7, n. 2, p.339-352, 2011. Disponível em: <https://revistas.unicentro.br/index.php/ambiencia/article/viewFile/1152/1270>. doi:10.5777/ambiencia.2011.02.11.

LACERDA, M.A.; SOARES, F.S.; COSTA, J.P.M.; MEDEIROS, R.S.; MEDEIROS, E.N.; CARVALHO, J.A.; SILVA, Z.L. Levantamento Florístico da Arborização Urbana nas Principais Vias Públicas Do Município de Boa Ventura - PB. Revista Brasileira de Gestão Ambiental - RBGA, v. 7, n. 4, p. 12-16, 2013. Disponível em: <http:// www.gvaa.org.br/revista/ index. php/RBGA>.

LOCKE, D.; BAINE, G. The good, the bad, and the interested: How historical demographics explain present-day tree canopy, vacant lot and tree request spatial variability in New Haven, CT. Urban Ecosyst, v. 18, p. 391-409, 2015. Disponível em: <https://doi.org/10.1007/s11252-014-0409-5> doi:10.10.1007/s11252-014-0409i.

OLIVEIRA-NEVES, P.; BARBOSA JUNIOR, A. S.; LOPES, B.S.; ANDREIS, D.; GONÇALVES, E.B.; LEMOS, G.M. Diagnóstico florístico-estrutural e potencial invasor da composição arbórea de praças municipais de São Gabriel, RS, Brasil. Pesquisas Botânica, n. 69, p.227-238, 2016. Disponível em: <http://www.anchietano.un isinos.br/publicacoes/botanica/botanica.htm>.

ROCHA, C. L. D.; FREITAS, J. F.; ALMEIDA, S. O.; SOUZA, A. C. R. Caracterização quantitativa da arborização urbana no município de itapuã do Oeste/RO. Saber Científico, v. $7, \quad$ n. 1, p. 1-12, 2018. Disponível em: $<$ http://revista.saolucas.edu.br/index.php/resc/article/view/764> doi:10.22614/rescv7-n1-764.

SANTOS, C.Z.A.; FERREIRA, R.A.; SANTOS, L.R.; SANTOS, L.I.; GOMES, S.H.; GRAÇA, D.A.S. Análise qualitativa da arborização urbana de 25 vias públicas da 
cidade de Aracaju - SE. Ciência Florestal, v.25, n.3, p.751-763, 2015. Disponível em: <http://www.scielo.br/pdf/cflo/v25n3/1980-5098-cflo-25-03-00751.pdf>. doi: 10.5902/1980509819678.

SARTORI, R.A.; MARTINS, G.A.C.; ZAÚB, A.S.; BRASIL, L.S.C. Urban aff orestation and favela: A study in A community of Rio de Janeiro, Brazil. Urban Forestry \& Urban Greening, v.40, p.84-92, 2019. Disponível em:< https://doi.org/10.1016/j.ufug.2018.10.004>. doi.org/10.1016/j.ufug.2018.10.004.

SCHALLENBERGER, L.S.; MACHADO, G. de O. Inventário da arborização na região central do município de Mangueirinha- PR. Revista da Sociedade Brasileira de Arborização Urbana, REVSBAU, v. 8, n. 1, p. 54-64, 2013. Disponível em: $<$ http://dx.doi.org/10.5380/revsbau.v8i1.66350>. doi:10.5380/revsbau.v8i1.66350.

SILVA, A.O.; ALVES, M.L.; MIRANDA, S.C. Levantamento da vegetação arbórea em praças no município de Itapuranga-GO. Magistra, v. 27, n.2, p. 179-187, 2015. Disponível em:<https://magistraonline.ufrb.edu.br/index.php/magistra/article/view/377>.

VIEIRA, J.G.P.; GONÇALVES, T.C.; PASIN, L.A.A.P. Levantamento Florístico De Espécies Arbóreas Na Praça Coronel José Vieira em Paraisópolis/MG. Revista Brasileira de Gestão Ambiental, v. 10, n.1, p.30-34, 2016. Disponível em: <https://doi.org/10.18378/rbga.v10i1.4323>. doi: 10.18378/rbga.v10i1.4323.

ZEA C., J.D.; BARROSO, R.F.; SOUTO, P.C.; JACOB S. SOUTO, J.S. Levantamento e diversidade da arborização urbana de Santa Helena, no semiárido da Paraíba. Agropecuária Científica no Semiárido, v.11, n.4, p.54-62, 2015. Disponível em:

http://revistas.ufcg.edu.br/acsa/index.php/ACSA/article/view/705/pdf>. doi: 10.30969/acsa.v11i4.705. 